
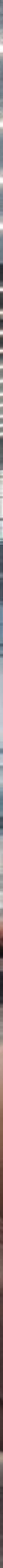


\title{
Un nuevo centro de producción de cultura contemporánea: la Fondazione Prada en Milán, Italia
}

Tommaso Cigarini

Investigador Independiente tommasocigarini@gmail.com

\section{Resumen}

La Fondazione Prada de Milán, Italia, es un paradigma y un ejemplo del mecenazgo moderno. En este documento se analiza de qué forma un museo de arte contemporáneo puede generar cambios positivos en el barrio donde se localiza, más aún si ese vecindario se ubica en una zona periférica de la ciudad que ha pasado por un proceso de degradación urbana. Veremos el caso de un museo como elemento rehabilitador de infraestructura y un espacio de estímulo para la creación y producción de cultura. El museo le da una nueva vida a una edificación abandonada que anteriormente estaba destinada a la producción industrial. Los amplios espacios de manufactura, hoy en día abandonados, son ideales para instalar obras de arte contemporáneo.

Palabras clave: Fondazione Prada, Miuccia Prada, Rem Koolhaas, museografía moderna, cultura contemporánea, arte contemporáneo

\begin{abstract}
The Fondazione Prada in Milan, Italy, is a paradigm and an example of modern patronage. This document analyzes how a museum of contemporary art can generate positive changes in the neighborhood where it is located, especially if that neighborhood is located in a peripheral area of the city that has gone through a process of urban degradation. We will consider the case of a museum as an infrastructure rehabilitation element and a stimulus space for the creation and production of culture. The museum gives a new life to an abandoned building that was previously destined for industrial production. The large manufacturing spaces, now abandoned, are ideal for installing works of contemporary art.
\end{abstract}

Keywords: Fondazione Prada, Miuccia Prada, Rem Koolhaas, modern museography, contemporary culture, contemporary art

En el mundo, Milán es conocida por la moda que genera. Su nombre es sinónimo de elegancia y buen vestir. La mayoría de turistas que llegan a esta ciudad italiana lo hacen con la intención de adquirir las últimas tendencias de la moda y ropa de diseñador.

Contrariamente a lo que se pensaría, en una ciudad donde las últimas tendencias y la moda bullen, Milán no contaba con un museo de arte contemporáneo, a pesar de que existían museos de diversos tipos, especialmente los de arte antiguo y renacentista. 
Se tiene una preciosa galería como el Pabellón de Arte Contemporáneo (PAC), construida y diseñada por el famoso arquitecto Ignazio Gardella en la década de los cincuenta del siglo pasado. En el PAC se organizaron exposiciones de muy alto nivel, pero siempre fue una galería ${ }^{1}$, no un museo.

En el 2010 se inauguró el Museo del Novecento, ubicado en la central Piazza del Duomo. Este museo expone lo mejor del arte italiano del siglo XX. Cuenta con colecciones de gran interés, que van del futurismo al arte povera. No obstante, de arte contemporáneo no había tanto, ya que las piezas expuestas más nuevas son del año setenta del siglo pasado. Por lo tanto, aún había una deuda con las obras que se han realizado desde el año 1970 al presente.

Además, las últimas administraciones políticas de la ciudad no se mostraban receptivas al arte contemporáneo, pues no promovieron la creación y el desarrollo de un museo que muestre el arte de nuestros tiempos.

En este panorama de la cultura milanesa, el arte contemporáneo encontró respuesta en el aporte de mecenas privados, tal es el caso de la señora Miuccia Prada, italiana, empresaria, diseñadora y dueña de una de las casas de moda más importantes del mundo, a la cual le dio su apellido: Prada. Es la tercera mujer más rica de Italia, hija de industriales, pero es también una mujer culta y sensible que, frente a la falta de interés de parte del sector político, decidió promover el arte contemporáneo en su ciudad. Logró su sueño y pudo crear un centro de cultura contemporánea llamado Fondazione Prada, el cual está abierto para todo tipo de público.

Al igual que los grandes mecenas del Renacimiento, Miuccia Prada cree fervientemente en el arte y brinda ayuda a los más interesantes artistas del momento. Desde 1993 promueve en Milán exposiciones de artistas nacionales e internacionales, conocidos y desconocidos, jóvenes y viejos, italianos y extranjeros. Sus exposiciones de arte siempre van a la vanguardia de la originalidad y la experimentación, incluso se toma el riesgo de contratar artistas casi desconocidos.

En un primer momento, la Fondazione Prada presentaba sus muestras en espacios reducidos de la ciudad, como por ejemplo la sede de Via Fogazzaro², que muy pronto se mostró limitada para albergar las exposiciones de arte que la señora Prada tenía en mente realizar. Por tal motivo, decidió comprar un espacio mucho más grande para construir un museo de arte contemporáneo, el cual estaría dedicado a la producción de cultura de nuestro tiempo.

El centro histórico de la ciudad de Milán, famoso por su conformación urbanística en forma de telaraña -distribución típica de la Edad Media-, no cuenta con muchos espacios físicos para nuevas construcciones, menos aún para un museo de arte contemporáneo que, según las estimaciones de la señora Prada, debería tener la extensión de una cuadra.

Por estos motivos, se eligió un terreno en la zona conocida como primera periferia sur de la ciudad para ubicar el museo de la Fondazione Prada. En este lugar se encuentran varias construcciones que fueron industriales en su momento, de enormes dimensiones y que estaban abandonadas.

Recordemos que desde la primera parte del siglo XX hasta los años setenta, Milán fue la primera ciudad industrial de Italia y contaba con grandes fábricas. Hacia el final de los años setenta, la producción en estas fábricas se mudó a otras partes del mundo y quedaron

1 http://www.pacmilano.it/ (consulta 15 setiembre del 2017).

2 http://www.fondazioneprada.org/ (consulta 15 setiembre del 2017). 


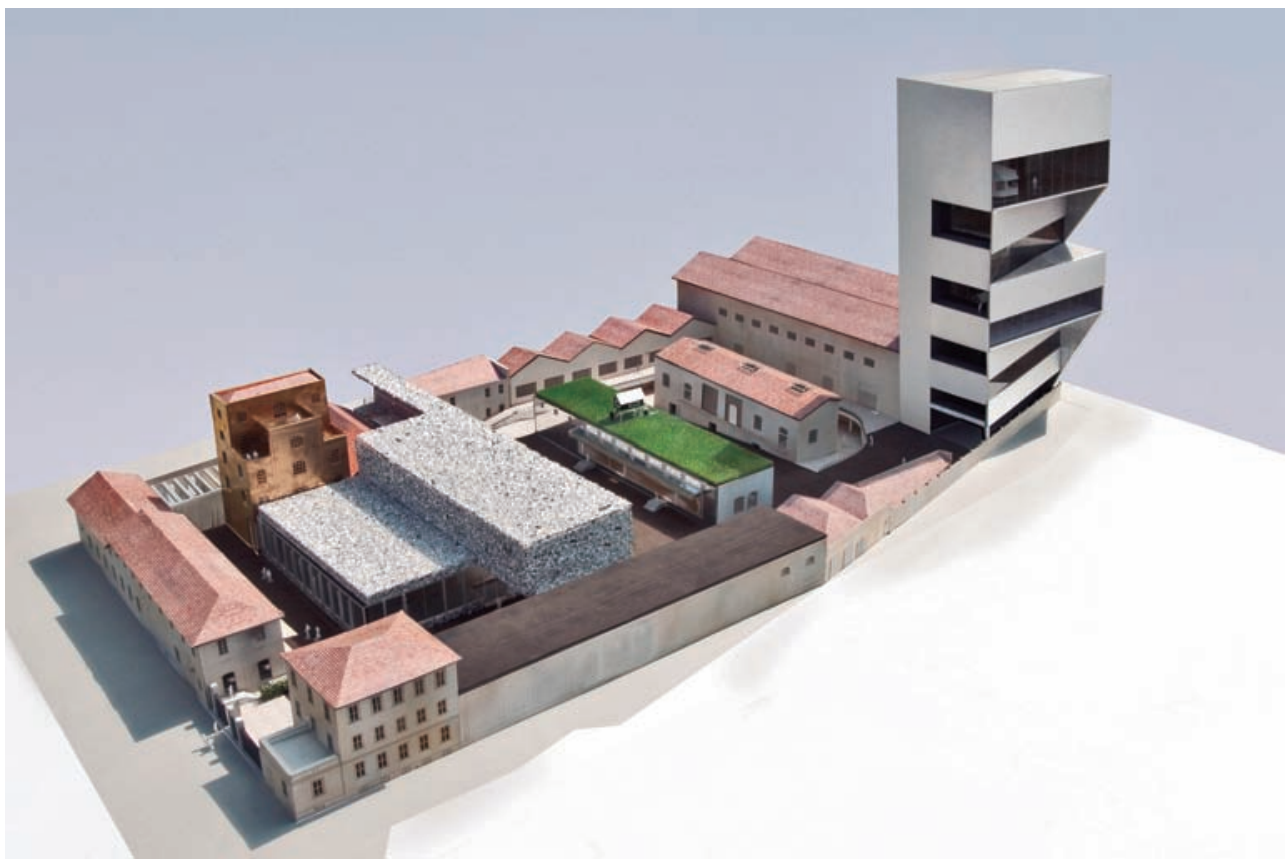

Fig. 1. Isometría de la Fondazione Prada. Imagen cortesía de OMA.

algunos enormes edificios abandonados hasta el día de hoy ${ }^{3}$. Estas edificaciones industriales, que tienen amplios espacios y una buena calidad arquitectónica, en la mayoría de los casos son demolidas por la municipalidad de la ciudad para construir edificios multifamiliares. De esta manera, se pierde el patrimonio industrial de la ciudad. Son muy pocos los casos en los que se les ha dado un nuevo uso a estos edificios industriales. La Fondazione Prada es uno de ellos.

En Largo Isarco, pasando el ferrocarril Milano Porta Romana, los Prada decidieron convertir en museo una antigua destilería de licores que se encontraba abandonada. Del proyecto de reconversión de licorería a museo fue encargado al arquitecto holandés Rem Koolhaas -del estudio OMA-, famoso por desarrollar arquitectura vanguardista y moderna ${ }^{4}$. No es la primera vez que Koolhaas trabaja para Prada. Ya ha realizado para esta famosa casa de moda tiendas, galerías y centros culturales por el mundo, desde Los Ángeles hasta Tokio. Con los años se ha creado entre Prada y el arquitecto holandés una sintonía y una conexión cultural muy fuerte. Es así como la visión vanguardista de la arquitectura se conecta con las últimas tendencias del arte contemporáneo.

El proyecto de conversión en museo tuvo como objetivo la conservación arquitectónica del complejo industrial (Fig.1), de manera que se han conservado casi todos los espacios existentes y añadido pabellones nuevos que eran necesarios para albergar la densidad del programa arquitectónico.

3 Milán hasta tiene millones de metros cubos de espacios exindustriales hoy (2017) sin uso y completamente abandonados. Falta un proyecto de reconversión de estos espacios a nuevos usos.

4 El proyecto de la Fondazione Prada ha empezado en el 2008 y ahora (2017) se está terminando la obra. El museo ya ha abierto sus puertas al público. 


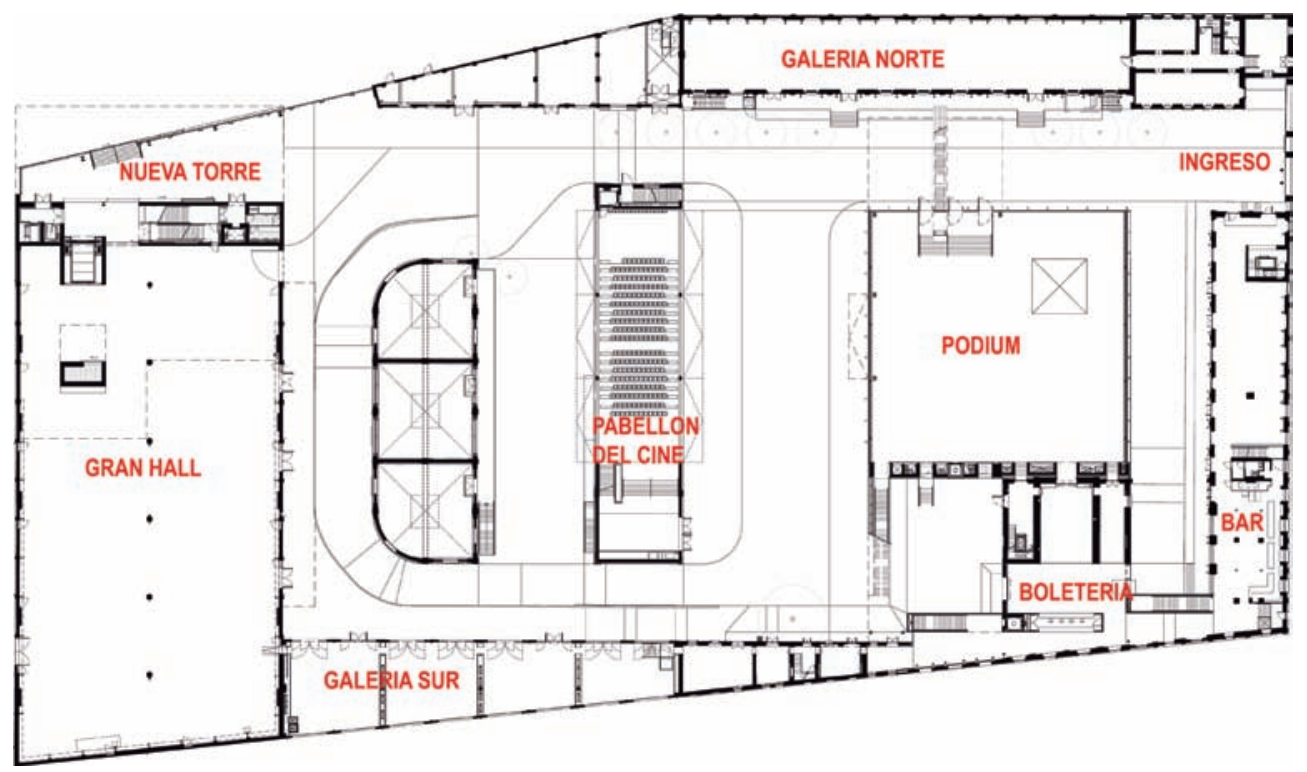

Fig. 2. Planta del primer piso de la Fondazione Prada. Imagen cortesía de OMA.

El lote tiene la forma de un rectángulo irregular; por el norte, el museo se abre hacía el ferrocarril de trenes; por el sur se abre a la ciudad industrial en fase de transformación. Durante la conversión se demolió un solo pabellón que estaba en muy mal estado y se conservaron los demás edificios del complejo. Durante la obra se excavó la zona central del lote para poder construir en el sótano los enormes depósitos que un museo de arte contemporáneo necesita. Estos depósitos se conectan con todos los pabellones. A su vez, estas galerías subterráneas permiten que se pueda trasladar con facilidad las obras de arte de un pabellón a otro.

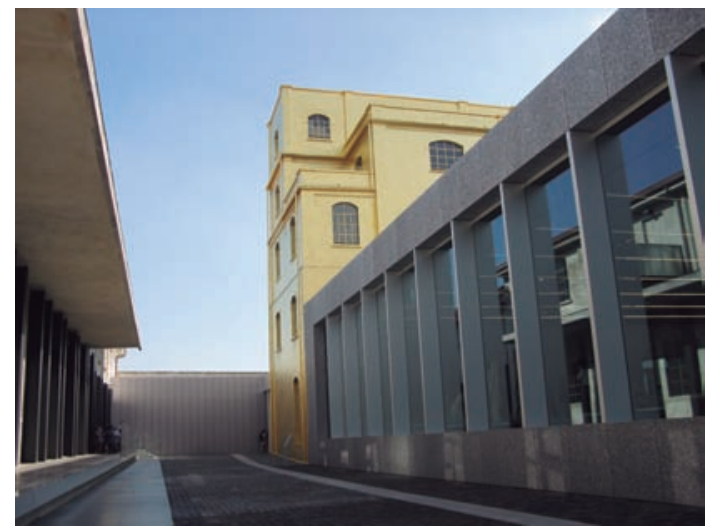

Fig. 3. Vista del Podium y, al fondo, la Torre de Oro. Foto: Miriam Saavedra.
En la superficie -entrando por el lado este del lote- encontramos el Podium, un nuevo pabellón de acero y vidrio, espacio que acoge exposiciones de arte contemporáneo (Fig.2). Este pabellón tiene, en el primer piso, paredes de vidrio que permiten ver las obras de arte desde el patio que lo rodea (Fig.3). Para ingresar a este pabellón tenemos que pasar por un hall donde encontramos la boletería, una librería y el guardarropa.

Este pabellón fue inaugurado en 2015 con la exposición arqueológica Serial Classic, en la cual se exhibían antiguas estatuas griegas y romanas colocadas sobre plataformas de diferentes niveles. Esta idea museográfica permite que el visitante explore el espacio como si estuviera caminando en una andenería moderna hecha de pedestales, planchas de acrílico y mármol travertino (Fig.4). La diferencia de un nivel a otro es de 18 centímetros, esto permite al visitante pasar de una plataforma a otra y también puede cambiar su perspectiva de observación de 
las esculturas antiguas. Después de esta exposición, el espacio ha sido usado para coreografías teatrales modernas y experimentales (Fig.5). La transparencia de las paredes del primer piso del Podium hace que el visitante tenga contacto visual con los diferentes patios del museo, dándonos la sensación de estar rodeados por arte (Fig.6).

El Podium está en contacto con la Torre de oro, estructura que ha sido conservada y pintada en toda su superficie exterior con hoja de oro. La idea es convertir la torre en el símbolo del nuevo museo y de la presencia del arte contemporáneo en la periferia de la ciudad. Desde el exterior, la torre es visible y su superficie de oro brilla, en especial en los días de sol (Fig.7). Todo el espacio de la Torre de oro acoge una instalación permanente de arte contemporáneo.

En la zona este del complejo encontramos un edificio longitudinal conocido como Luna Rossa archive, en donde está el bar Luce del museo, hecho por el director de cine Wes Anderson, quien ha recreado un bar típico milanés de los años cincuenta

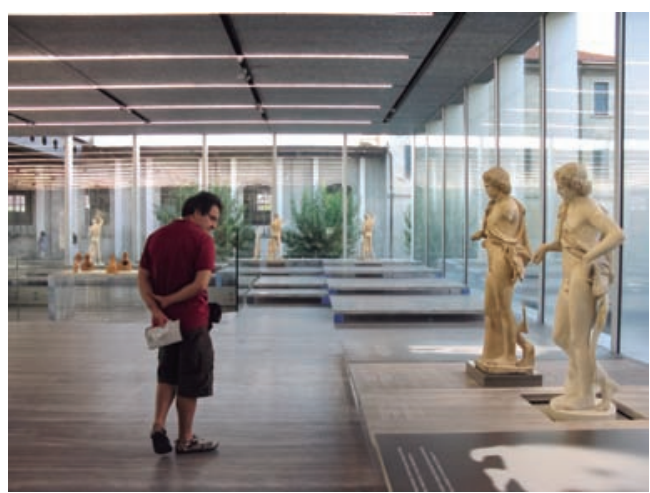

Fig. 4. Vista del interior del Podium sala de exposiciones temporales. Foto: Miriam Saavedra.

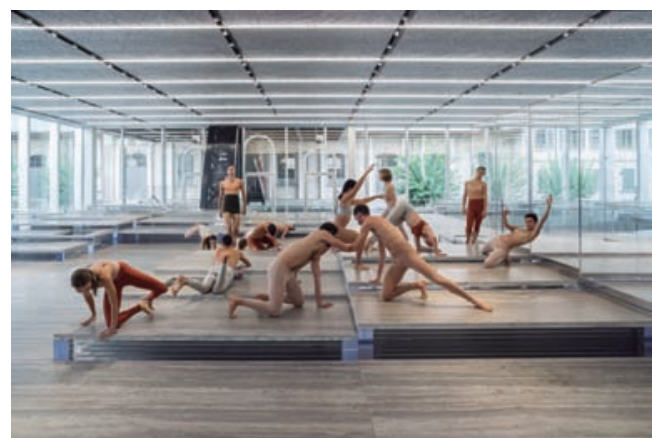

Fig. 5. Vista del interior del Podium uso para una coreografía. Foto: Ela Bialkowska.

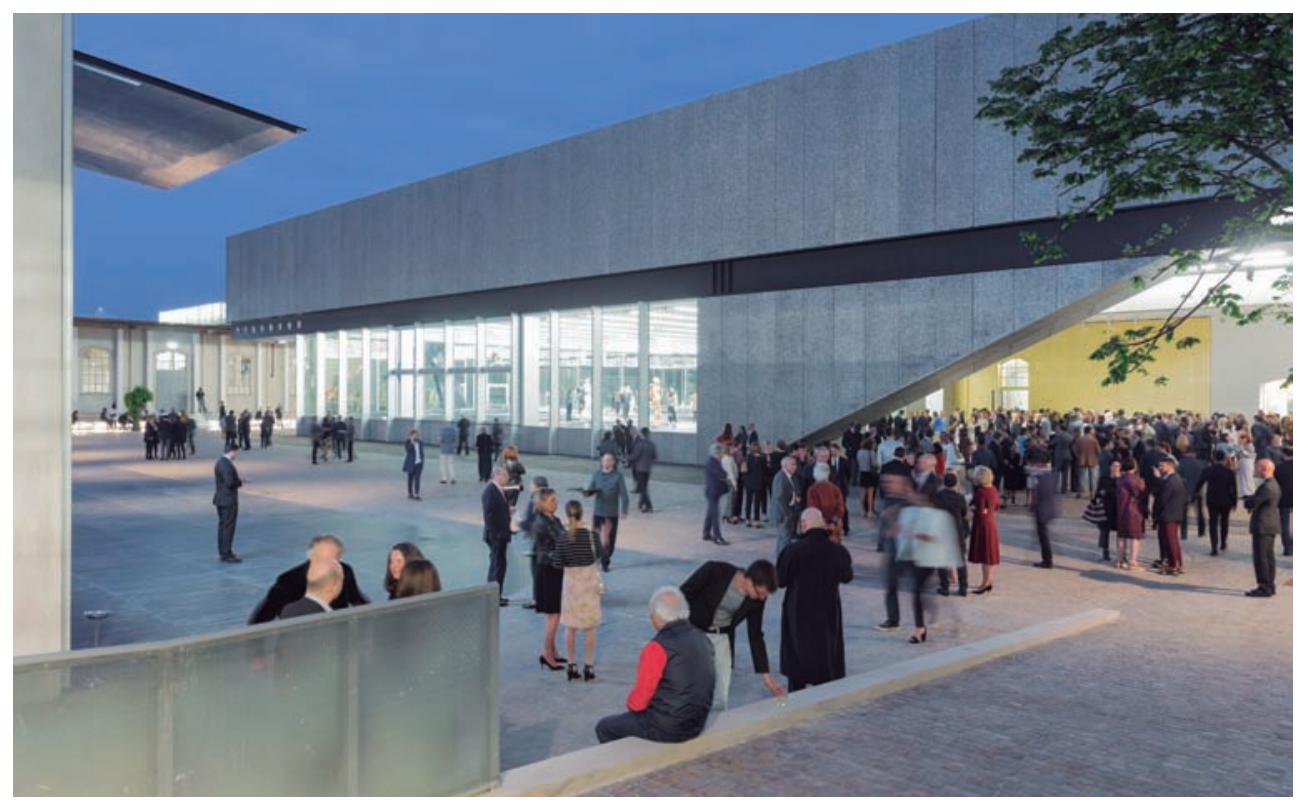

Fig. 6. Vista del exterior del Podium desde el patio. A la izquierda el pabellón del cine. Foto: Iwan Baan 


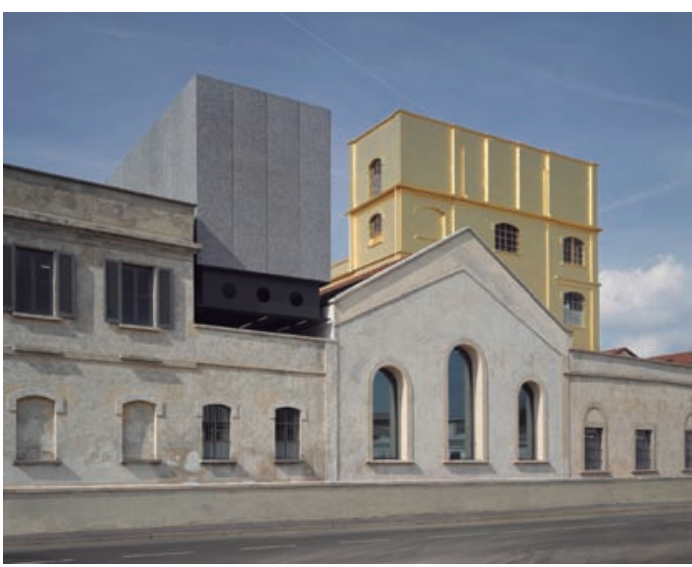

Fig. 7. Vista de la Torre de Oro desde la calle. Foto: Bas Princen.

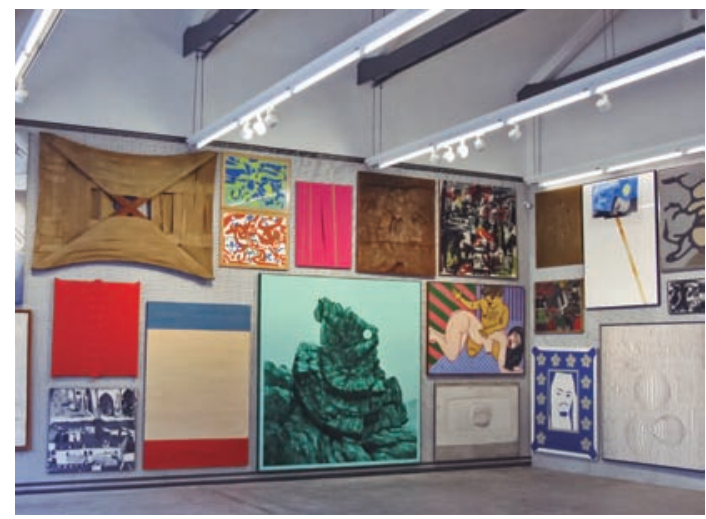

Fig. 8. Vista de una sala de la Galería Sur colección permanente. Foto: Miriam Saavedra.

del siglo pasado. Al costado de ese bar -en el mismo edificio-, encontramos los archivos del museo y una biblioteca para niños.

El recorrido continúa con una serie de salas que conforman la galería sur, las cuales exhiben la colección de arte de Miuccia Prada, conformada por pinturas y esculturas de arte internacional de los siglos XX y XXI. Las obras son numerosas y recubren las paredes de las galerías, y están colgadas de diversas rejas de aluminio (Fig.8). Esto permite que al centro de las salas puedan hacerse instalaciones de arte de diferente tipo.

Superadas estas galerías, llegamos al Gran Hall, un enorme espacio que tenía uso industrial y ahora está destinado a la exposición de esculturas e instalaciones. Desde el Gran Hall podemos acceder a la Nueva Torre, un edificio de concreto armado de nueve pisos. Cada piso tiene una altura distinta -de piso a techo- que va aumentando progresivamente desde los 3,3 metros hasta los 8 metros. Las dimensiones de las diversas salas, de piso a techo, permiten acoger obras de gran formato en altura y tamaño, condición típica en el arte contemporáneo.

La Nueva Torre acoge espacios para exposiciones temporales, así como un auditorio, un restaurante, cocina y servicios. Cada piso, a través de paredes de vidrio alternadas, tiene una vista distinta de la ciudad. Así, un piso se abre hacia el norte, mirando la ferrovía; otro piso se abre hacia el este, mirando al antiguo complejo industrial del museo.

El material de esta torre es de concreto expuesto blanco, el cual ha sido fabricado con fragmentos pulverizados de mármol de Carrara, el mismo mármol que usaba Michelangelo en el Renacimiento para crear sus esculturas (Fig.9). Este concreto blanco es visto en el exterior y al interior de las salas. Su textura y color garantiza la belleza de las superficies y la neutralidad cromática necesarias para las salas del museo.

A diferencia de los otros niveles, que encuadran la ciudad desde una perspectiva diferente, en el sexto piso de la torre encontramos el restaurante, desde donde el público del museo puede tener una vista panorámica de toda la ciudad de Milán.

Vistos en planta, cada piso tiene una forma diferente. La forma de las salas varía desde rectangular o trapezoidal, hasta triangular. La altura de la torre es de 60 metros, aproximadamente como un edificio de 17 pisos. Su presencia se nota desde muy lejos y es un punto de referencia urbano (landkmark); es el símbolo del renacimiento artístico y cultural de la periferia industrial de Milán. 


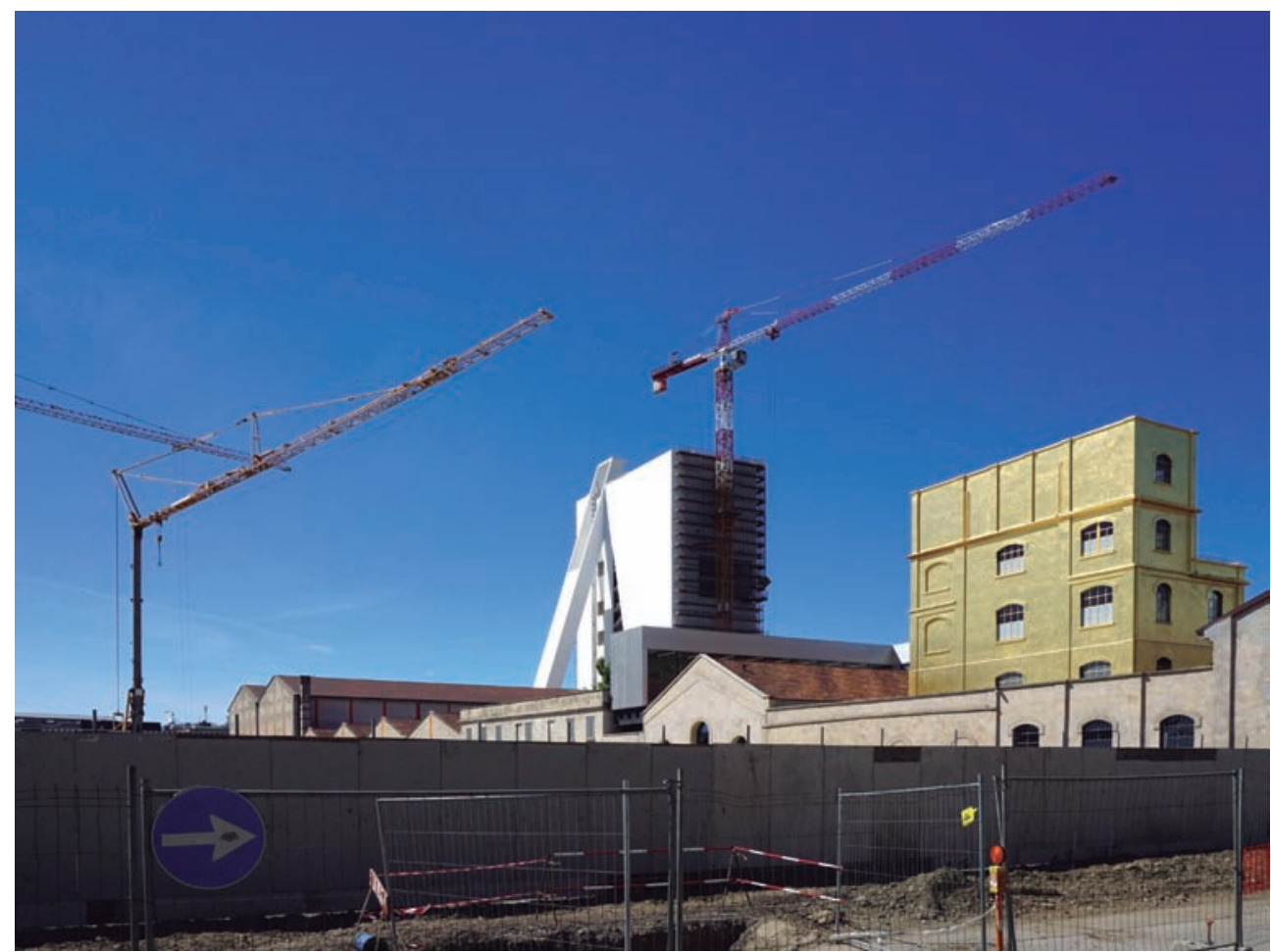

Fig. 9. Vista de la Nueva Torre en construcción desde la calle. Foto: OMA.

Al costado de la nueva torre encontramos La Cisterna, un pabellón que ya existía y que ha sido conservado y transformado en un espacio para instalaciones artísticas.

Entre La Cisterna y el Podium encontramos el Pabellón del Cine, un auditorio rectangular que puede ser usado para proyecciones de películas artísticas, conferencias, presentaciones de exposiciones de arte, espectáculos de danza o eventos (Fig.10). Las paredes externas de este pabellón han sido forradas con paneles de aluminio reflejantes que tienen la función de servir como espejos. De esta forma, los visitantes y el antiguo complejo industrial quedan reflejados en las paredes, dilatando aún más el espacio del museo.

Las paredes laterales del cine también pueden abrirse durante el verano, transformando el pabellón en un espacio multiuso que pone en contacto el espacio exterior e interior en eventos ligados al arte.

Toda la parte norte del lote ha sido conservada y acoge a la Galería Norte, un espacio para exposiciones temporales, archivos y oficinas.

En conclusión, podemos decir que Miuccia Prada ha querido que la Fondazione Prada sea mucho más que un museo de arte contemporáneo. Es un centro de producción de cultura. Por esta razón, casi todos los espacios de este enorme complejo están destinados a exposiciones temporales. El museo en total tiene 28000 metros cuadrados, de los cuales 11800 están destinados a salas de exposiciones temporales, es decir, casi la mitad del espacio total del museo. La idea es que los artistas y los mismos ciudadanos se apropien del museo para hacer arte en todas sus formas y manifestaciones. Hoy en día, el museo está casi terminado. Se prevé que el próximo año abrirá al público la última parte del museo: la nueva torre. 


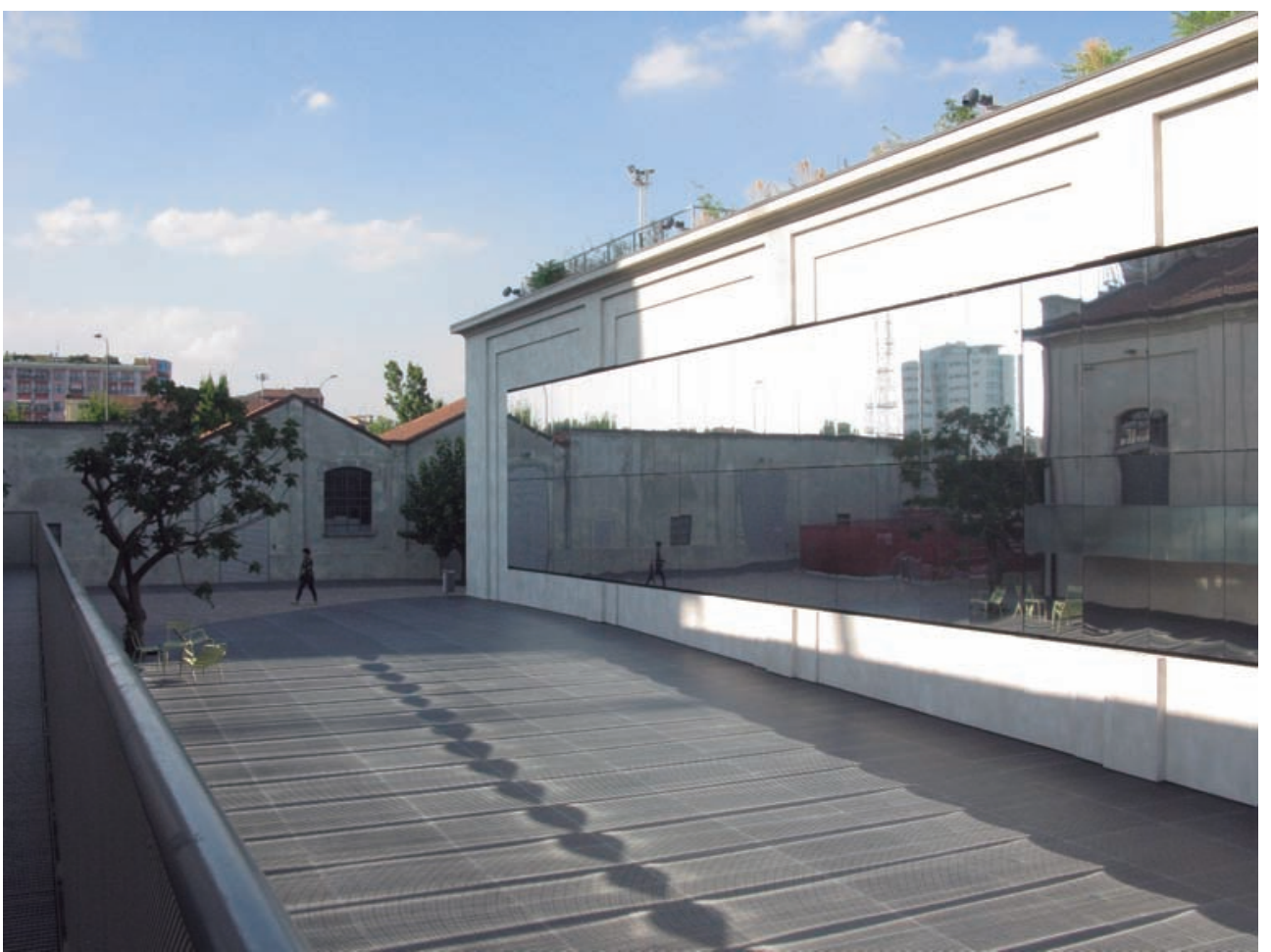

Fig. 10. Vista del interior del Pabellón del cine. Foto: Miriam Saavedra.

Se puede decir que hasta el momento la respuesta de la ciudad, del barrio y de sus habitantes ha sido positiva. Los artistas de la zona están abriendo sus talleres al público los fines de semana, se han abierto bares, galerías y centros culturales cerca al museo. Lo que antes era una zona industrial y abandonada de la ciudad, ahora se ha convertido en un importante polo cultural. Esta es la prueba de que un nuevo museo puede ser el catalizador de un renacimiento cultural e impulsar procesos de rescate cultural de zonas que sufrieron una degradación urbana.

Este ejemplo nos hace reflexionar y pensar que en la ciudad de Lima -que cuenta con un gran patrimonio de culturas precolombinas y un gran número de artistas-, cada día se hacen más necesarios los museos. Si bien el Museo de Arte de Barranco (MAC) demuestra un interés de la ciudad por el arte contemporáneo, sería necesario que ese arte llegue también a las zonas periféricas de la ciudad a través de una nueva generación de museos descentralizados, que sean a su vez espacios multiusos que sirvan a la comunidad y con los cuales el pueblo se identifique. El nuevo museo del siglo XXI tiene esta naturaleza: no es solo un espacio de conservación y exhibición del arte, es además un espacio de producción de cultura contemporánea. 